\title{
Assessment the Effects of Low Power Laser Light on Some Virulent Factors of Klebsiella pneumoniae Isolated from Respiratory Tract Infections
}

\author{
Diana Fadhil Al-Saadi ${ }^{1 *}$, Mouruj A. Al-Aubydi ${ }^{1}$ and Layla M. Al-Ameri ${ }^{2}$ \\ ${ }^{1}$ Biotech. Dept. University of Baghdad/College of science, Iraq \\ ${ }^{2}$ University of Baghdad/ Institute of laser for postgraduate studies, Iraq \\ *Corresponding author
}

\section{Keywords \\ Klebsiella pneumoniae, Low power laser light, Methylene blue, Rhodamine dyes and Virulent factors. \\ Article Info \\ Accepted: \\ 19 June 2017 \\ Available Online: 10 August 2017}

\section{A B S T R A C T}

One of the most opportunistic and nosocomial infections causative agent is $K$. pneumoniae, its tendency to be chronic and often display multidrug-resistance phenotypes that are commonly caused by the presence of Extended-spectrum $\beta$-lactamases or carbapenemases, making it difficult to choose appropriate antibiotics for treatment. Opportunistic K. pneumoniae mostly affects those with compromised immune systems or who are weakened by other infections. Its colonization can be made further infection in the human especially in the urinary tract, and respiratory tract. Thus this study was a goal to assess the effect of low power laser light on the virulence factors of Klebsiella pneumoniae. The results showed $17.9 \%$ were characterized as Klebsiella pneumoniae from 151 cases of respiratory tract infections. Antimicrobial sensitivity test showed elevation in the resistance of these isolates for most usable antimicrobial agents, the most resistant isolate was selected. Another selection was done depending on the type of laser dye, the result of using methylene blue dye at $650 \mathrm{~nm}$. Showed the numbers of the colony were varied according to the conc. of dye, they were direct decreases due to the decreasing of dye conc. with time. Meanwhile, it became smaller with rough texture when cultured on MaCconkey agar, and microscopically the bacterial capsules showed slight thickness around the bacteria in compared with the control isolate. As well as there was changing in the degree of glucose fermentation. On the other hand, the antimicrobial sensitivity results showed, the exposed isolate was changed the sensitivity condition to resistance for both of Ciprofloxacin (CIP) and Tobramycin (TN). While using another laser dyes (Rhodamine110 and Anthocyanin) at $532 \mathrm{~nm}$. There was variation in the colony size and texture. Meanwhile microscopically, the bacterial capsules elucidated slight thickness around the bacteria in compared with the control isolate. Inaddition to the changing in some biochemical tests, as well as the antimicrobial sensitivity results showed heterogeneities toward several antimicrobial agents. On the other hand, the results of biofilm formation showed a negative result for all tests.

\section{Introduction}

Klebsiella pneumoniae, is a member of the family Enterobacteriaceae, rod-shaped, Gramnegative, lactose-fermenting bacilli with a luxurious capsule. Typical $K$. pneumoniae is an opportunistic pathogen that is widely found in the mouth, skin, and intestines as normal flora, epidemiologically play a role in the hospital as nosocomial pathogen through contaminating medical devices (Podschun et al., 1998). Nosocomial infections caused by 
$\mathrm{K}$. pneumoniae tend to be chronic due to the two following major reasons: $K$. pneumoniae biofilms formed in vivo protect the pathogen from attacks of the host immune responses and antibiotics (Jagnow et al., 2003), and often display multidrug-resistance phenotypes that are commonly caused by the presence of Extended-spectrum $\quad \beta$-lactamases or carbapenemases, making it difficult to choose appropriate antibiotics for treatment (Paterson et al., 2004; Munoz-Price et al., 2013). Opportunistic $K$. pneumoniae mostly affects those with compromised immune systems or who are weakened by other infections. Its colonization can be further found in the urinary tract, respiratory tract, gastrointestinal tract and blood. At least 78 capsular (K antigen) serotypes have been recognized for K. pneumoniae (Pan et al., 2008; Hsu et al., 2013).

A few serotypes (including predominantly K1 and K2) have a unique hypermucoviscous (hypervirulent) phenotype due to increased production of capsule polysaccharide (CPS), Hypervirulent $K$. pneumoniae is highly invasive and may cause life-threatening and often community-acquired infections, such as pyogenic liver abscess, meningitis, necrotizing fasciitis, endophthalmitis and severe pneumonia (Shon et al., 2012). This bacteria has many virulence factors as a whole make it pathogenicity, included Capsule (Steward et al., 2001). In addition to the different types of adhesions or colonization factors like Pili (fimbriae) such as Type I pili or mannose-sensitive Klebsiella hemagglutination (MS/K-HA), Type III Pili or mannose-resistant Klebsiella hemagglutination (MR/K-HA) (Podschun et al., 1991), both can contribute to biofilm formation (Podschun et al., 1991; Podschun et al., 1998). Some of this bacteria can produce a thick layer of extracellular biofilm as a virulence factor that helps the organism attach to living or abiotic surfaces, and preventing the effects of antimicrobial agents (Vuotto et $a l ., 2014$ ) and siderophore production (Brooks et al., 2001).

The laser "Light Amplification by Stimulation Emission of Radiation" its concept is a particle of light with energy of a particular frequency could stimulate electrons to emit radiation of light of the same frequency. This phenomenon is the key to the operation of the laser (Saunders et al., 1980). In the life science, medical science and even in nuclear fusion, many research projects are being carried out using laser (Shimoda, 1984). Different researchers have documented the effect of this technique on microorganisms. This technique was applied by using different types of dyes, called laser dyes, its organic compounds that relax radioactively after optical excitation, emitting in the visible or infrared range (Alsalhi et al., 2007). Most laser dyes operate with materials that belong to the class of xanthenes derivatives especially Rhodamine dyes. They cover the wavelength region from 500-700 nm and generally very efficient (Balaji et al., 2011). Because of multidrug resistance in Gramnegative bacteria, particularly Enterobacteriaceae such as E. coli and $K$. pneumoniae, has become one of the biggest global concerns. Infections with these bacteria lead to prolonged hospital admissions and higher mortality rates, and a worldwide using the laser, this study was concerned with the effect of low power laser light on some virulence factors, and biochemical activities of pathogenic $K$. pneumoniae isolated from respiratory tract infection.

\section{Materials and Methods}

\section{Samples collection}

Samples of (151) episodes of lower respiratory tract infection were collected from Baghdad/Iraq (Central teaching of Pediatric, 
Al-Yarmouk Teaching, and Baghdad medical city) hospital, during a period of November /2016 - February/2017. The specimens were cultured on MaCconkey agar (LAB M, U. K.) and incubated for $18-24 \mathrm{~h}$ at $37 \mathrm{C}$.

\section{Identification of the isolates}

Specimens isolates were identified depending on colony morphology, Microscopic examination, biochemical tests elaborated by Epi20E (bio-merieux/France), chromo agar as confirmatory tests and Congo red agar prepared from $(5.2 \mathrm{~g}$ of B.H.I.A., $5 \mathrm{~g}$ of sucrose, $0.08 \mathrm{~g}$ of Congo red in $100 \mathrm{ml}$ D.W ).

\section{Antimicrobial sensitivity test}

Antimicrobial sensitivity test was done for each isolate characterized as Klebsiella pneumonia by using 10 different types of antimicrobial disks, included (Erythromycin, Ciprofloxacin, Tobramycin, Methicillin, Gentamycin, Imipenem, Cloxacillin, Trimethoprim, Ampicillin, and Streptomycin) (Mast Diagnostics, Mast Group Ltd., Merseyside, U.K.) which are deemed as the most local usable antimicrobial agents for variable types of infection.

The isolate that appeared resistant for most usable antimicrobial disks was selected for further experiments.

Primary selection by using low power laser light

\section{Activation and preparation of bacterial isolate}

Activation of selected isolate for $18 \mathrm{~h}$ using brain heart infusion broth (HIMEDIA/India), subsequently adjusted the dilution of the isolate in comparison with MaCcforland $1 \times 10^{8}$ bacteria $/ \mathrm{ml}$.

\section{Calculation and preparation of laser dye}

Methylene blue was selected as laser dye for primary bacterial excitation. According to the (Von Bathen et al., 2014), the amount of methylene blue was calculated and prepared at a concentration of $10^{-4}$ (stock solution dye) depending on the following equations.

$\mathrm{C}=\mathrm{Wt} . \times \mathrm{Mw} . \times \mathrm{V} . / 1000$

Serial dilutions $\left(10^{-5}\right.$ and $\left.10^{-6}\right)$ were prepared from the stock one according to the following equation. $\mathrm{C} 1 \times \mathrm{V} 1=\mathrm{C} 2 \times \mathrm{V} 2$

\section{Preparation of the isolate/ dye mixture}

Three copies for each methylene blue dye concentration $\left(10^{-6}, 10^{-5}, 10^{-4}\right)$ were prepared tubes, each one included $100 \mu \mathrm{l}$ of usable conc., and then aliquot of $1000 \mu \mathrm{l}$ from $10^{8}$ isolate suspension transferred to these tubes, subsequently each tube was plotted to the low power laser light (CW Diode Laser/4.5 volt D.C, $800 \mathrm{~mA}$ ) at $650 \mathrm{~nm}$ for different time (1,2 and 3)min. after a while, a loop full was taken and cultured on MuellerHinton agar and MaC conkey agar. Depending on the number of bacterial growth after exposure, a series of experiments were done to obtain the best dilution and amount for isolate suspension and methylene blue dye that affected on the bacterial virulence factors number of the colony, morphology, biochemical activities, biofilm and capsular formation, and sensitivity to antimicrobial agents).

\section{Finally selection by using low power laser} light

According to primary experiment, the best concentration for both isolate suspension and laser dye conc. were obtained with determining the suitable time for plotting to low power laser light, that affected on the 
bacterial virulence factors with less bacterial lethality.

Thus $500 \mu \mathrm{l}$ of $10^{7} \mathrm{CFU}$ isolate suspension with $100 \mu \mathrm{l}$ of $10^{-4}$ methylene blue dye was used and mixed, and then plotted to low power laser light at $650 \mathrm{~nm}$ for $2 \mathrm{~min}$. After a while, a loop full was taken and cultured on (MaCconkey, Congo red) agar and Chromo agar as a confirmatory test. This experiment was done for the first day, and then by using the same exposed isolate, the experiment was repeated five times for five days subsequently.

Other experiments were done by using wavelength $532 \mathrm{~nm}$. (DPSS Laser /Diode Pumped Solid state laser), for different laser organic dyes Rhodamine 6G (Lambda Physik, USA), Rhodamine 110 (Lambda Physik, USA) and Anthocyanin (locally prepared from a plant source).The same steps for the previous experiment were carried out for each dye.

The result of plotted selected colony was elaborated to antimicrobial sensitivity test and Epi 20E for all sixth passages in comparison to virulent isolate.

\section{Results and Discussion}

\section{Identification bacterial isolates}

Several tests such as microscopically, colony morphology and biochemicals were made to identify bacterial isolates. According to (Holt et al., 1994), the characteristic parameters showed, $27(17.9 \%)$ were Klebsiella pneumoniae from 151 total number of respiratory specimens, through a Gramnegative, non-motile, small straight rods and arranged singly or in pairs under light microscope, in addition to a mucoid texture, large size, round regular colonies and lactose fermenter on MacConkey agar (Figure 1), and a positive result as Klebsiella pneumonia for API 20E (Fig. 3) and confirmatory test by chromo Agar (Fig. 2). Furthermore, the results of biofilm formation on Congo red showed a negative result (Fig. 4).

\section{Antimicrobial sensitivity test}

Depending on (C.L.S.I, 2015) guideline, antimicrobial sensitivity test was done for 27 Klebsiella pneumoniae isolates. The results appeared increasing in resistance to antimicrobial agents as shown in table 1, elucidated that the resistance to Cloxacillin, Erythromycin, Methicillin, trimethoprim, Streptomycin, Tobramycin, Ampicillin, Gentamicin, Ciprofloxacin, and Imipenim were $(100,85.2,66.6,62.9,55.5,48.1,44.4$, $33.3,33.3,22.2) \%$ respectively.

The isolates that appeared resistance for most usable antimicrobial disks was selected for further laser experiments (Fig. 5).

The primary selection by using low power laser light with methylene blue dye

The results of the primary selection by using $10^{8}$ CFU isolate suspension with different conc. of methylene blue dye, shown according to the bacterial growth (the no. of colonies and its morphology), the numbers of the colony were varied according to the conc. of dye, they were direct decreases due to the decreasing of dye conc. with time table 2 .

The diluents of $10^{-4}$ of Methylene Blue dye with 2 minutes exposure was selected as a reason of the colony diameter $(2 \mathrm{~mm})$ which reflects the bacterial (CFU) ability to grow. In spite of the no. of the colony in this conc. which was represented more than other usable conc., therefore the further experiments were done with less bacterial conc. hence we selected $10^{7} \mathrm{CFU}$ 
Finally selection by using low power laser light

The suitable conditions were applied, the results showed changing in colony size, it becomes smaller than the control with rough texture when cultured on MaCconkey agar (Fig. 6), and microscopically appearance, the bacterial capsules showed slight thickness around the bacteria in compared with the control isolate. Biochemical changing occurred in the degree of glucose fermentation, it varies in its color from yellow to brown for all 6th passages (Fig. 9). As well as the antimicrobial sensitivity results showed several variations in the degree of sensitivity, the exposed isolate showed changing of sensitivity against both of Ciprofloxacin (CIP) and Tobramycin (TN) to resistant conditions (Table 3), this result may as (Piatti et al., 2008) reported that,a contrary relation between virulence and resistance to quinolones has been established in some studies. Quinolones and fluoroquinolones resistant strains show reduced virulence and, while the susceptible strains are more virulent. Thus a number of virulence factors carried, and the presence or absence of specific virulence factors, as well as their expression, may occur under certain conditions. While resistance to aminoglycosides and its relation with virulence is still unknown as (Horcajada et al., 2005) mentioned, the resistance to some members of aminoglycoside agents was associated with a reduction in the prevalence of fimH which is the main structure in type 1 fimbriae that related with the first step of bacterial colonization. In addition to an increase in iutA prevalence, in comparison to susceptible isolates. On the other hand, the results of biofilm formation showed a negative result for all passages which was represented no changes was occurred in compared with control one.
The results of other experiments were done by using wavelength $532 \mathrm{~nm}$. for another two organic laser dyes (Rhodamin 110 and Anthocyanin). The results of exposure by using rhodamin 110 dye showed changing in colony size, it becomes larger than the control with a smooth texture, when cultured on MaCconkey agar (Fig. 7), and microscopically the bacterial capsules appeared slight thickness around the bacteria in compared with the control isolate. In addition to the changing in the some biochemical tests such as ADH (Arginine dehydrogenase) and ODC (Ornithine decarboxylase) tests, it varies from the negative result (yellow color) in the control and for the fifth passages to a positive result (red color) in the last 6th passage (Fig. 10). As well as the antimicrobial sensitivity results showed several variations occurred in the degree of sensitivity, the exposed isolate showed indolent variation for SAM, its changed from resistance to a sense one in the 1 st passage, and throughout 2ed, 4th, and 6th passages the isolate became intermediates. the conversion of the exposed isolate from resistant to intermediate or sensitive for these types of beta-lactam antimicrobial agents may due to some genetic changes were occurred that lead to counteract resistance to $\beta$-lactams included several mechanisms including modification of penicillin-binding proteins, loss of porins, production of $\beta$-lactamases, or over expression of efflux pumps as reported Whereas the isolate converted to intermediate to streptomycin (S) in the 3rd and 4th passages while to sensitive in the 6th passage, and the changing from intermediate for Gentamycin (GM) to sensitivity in 2ed passages. Because there are different mechanisms that made bacterial cell converted to resistant to these types of antimicrobial agents such as modification of the 16S RNA of bacterial 30S ribosomal subunit by mutation or methylation of the aminoglycoside binding site. 
Table.1 The number and percentage of Klebsiella pneumoniae isolates sensitivity toward antimicrobial agents

\begin{tabular}{|l|l|l|l|}
\hline Antibiotic & Resistant \%(no.) & Intermediate\%(no.) & Sensitive\%(no.) \\
\hline Gentamycin & $33.3(9)$ & 0 & $66.7(18)$ \\
\hline Impenime & $22.2(6)$ & $11.1(3)$ & $66.6(18)$ \\
\hline Ciprofloxacine & $33.3(9)$ & $14.8(4)$ & $51.9(14)$ \\
\hline Methicilline & $66.6(18)$ & $14.8(4)$ & $18.6(5)$ \\
\hline Trimethoprime & $62.9(17)$ & $14.8(4)$ & $22.2(6)$ \\
\hline Streptomycine & $55.5(15)$ & $18.5(5)$ & $26(7)$ \\
\hline Cloxaciline & $100(27)$ & 0 & 0 \\
\hline Erythromycin & $85.2(23)$ & $3.7(1)$ & $11.1(3)$ \\
\hline Tobramycine & $48.1(13)$ & $2.7(1)$ & $48.1(13)$ \\
\hline Ampiciline & $44.4 \%(12)$ & $14.8 \%(4)$ & $40.8(11)$ \\
\hline
\end{tabular}

Table.2 The number of colonies with different methylene blue dye conc. according to the time

\begin{tabular}{|l|l|l|l|}
\hline $\begin{array}{l}1 \mathrm{ml} \text { of } 10^{8} \text { bacterial } \\
\text { suspension with } 0.1 \mathrm{ml} \\
\text { of } 10^{-4} \mathrm{M} . \mathrm{B}\end{array}$ & $\begin{array}{l}1 \mathrm{~min} \\
>561\end{array}$ & $\begin{array}{l}2 \mathrm{~min} \\
>438\end{array}$ & $\begin{array}{l}3 \mathrm{~min} \\
>432\end{array}$ \\
\hline $\begin{array}{l}1 \mathrm{ml} \mathrm{of} 10^{8} \text { bacterial } \\
\text { suspension with } 0.1 \mathrm{ml} \\
\text { of } 10^{-5} \mathrm{M} . \mathrm{B}\end{array}$ & $\begin{array}{l}1 \mathrm{~min} \\
>506\end{array}$ & $\begin{array}{l}2 \mathrm{~min} \\
>493\end{array}$ & $\begin{array}{l}3 \mathrm{~min} \\
>296\end{array}$ \\
\hline $\begin{array}{l}1 \mathrm{ml} \text { of } 10^{8} \text { bacterial } \\
\text { suspension with } 0.1 \mathrm{ml} \\
\text { of } 10^{-6} \mathrm{M} . \mathrm{B}\end{array}$ & $\begin{array}{l}1 \mathrm{~min} \\
>420\end{array}$ & $\begin{array}{l}2 \mathrm{~min} \\
>350\end{array}$ & $\begin{array}{l}3 \mathrm{~min} \\
>250\end{array}$ \\
\hline
\end{tabular}

Table.3 Antimicrobial sensitivity test for isolate suspension with the methylene blue dye that exposure to low power laser light at $650 \mathrm{~nm}$ for $2 \mathrm{~min}$

\begin{tabular}{|l|l|l|l|l|l|l|l|}
\hline Antibiotic & control & 1Pass. & 2Pass. & 3Pass. & 4Pass. & 5Pass. & 6Pass. \\
\hline IMI & 3.1 & 2.1 & 2.1 & 1.9 & 2.0 & 2.3 & 2.0 \\
\hline CIP & 3.0 & 0 & 0 & 0 & $<1.0$ & 1.1 & 1.0 \\
\hline GM & 1.3 & 1.6 & 1.8 & 1.6 & 1.6 & 1.9 & 1.6 \\
\hline CX & 0 & 0 & 0 & 0 & 0 & 0 & 0 \\
\hline TS & 0 & 0 & 0 & 0 & 0 & 0 & 0 \\
\hline MEC & 1.6 & 1.6 & 2.0 & 1.5 & 1.6 & 1.9 & 1.6 \\
\hline E & 0 & 1.0 & 0 & 0 & 0 & 1.0 & $<1.0$ \\
\hline TN & 1.8 & 0 & 0 & 0 & 0 & 0 & $<1.0$ \\
\hline SAM & 1.0 & 0 & 0 & 0 & 0 & 0 & 0 \\
\hline S & 0 & 0 & 1.1 & 1.0 & 1.0 & 1.0 & $<1.0$ \\
\hline
\end{tabular}


Table.4 Antimicrobial sensitivity test for isolate suspension with Rhodamine 110 dye that exposure to low power laser light at $532 \mathrm{~nm}$ for $2 \mathrm{~min}$

\begin{tabular}{|l|l|l|l|l|l|l|l|}
\hline Antibiotic & Control & 1pass. & 2pass. & 3pass. & 4pass. & 5pass. & 6pass. \\
\hline IMI & 3.1 & 3.0 & 3.0 & 3.2 & 3.0 & 3.1 & 3.1 \\
\hline CIP & 3.0 & 3.0 & 2.9 & 3.0 & 2.9 & 3.0 & 2.8 \\
\hline GM & 1.3 & 1.5 & 1.6 & 1.6 & 1.5 & 1.5 & 1.5 \\
\hline CX & 0 & 0 & 0 & 0 & 0 & 0 & 0 \\
\hline TS & 0 & 0 & 0 & 0 & 0 & 0 & 0 \\
\hline MEC & 1.6 & 1.7 & 1.6 & 1.8 & 0 & 0 & 0 \\
\hline E & 1.0 & 0 & 0 & 0 & 0 & 0 & 0 \\
\hline TN & 1.8 & 1.8 & 2.0 & 2.0 & 1.7 & 2.0 & 1.8 \\
\hline SAM & 1.0 & 1.4 & 1.4 & 1.8 & 1.6 & 1.6 & 1.6 \\
\hline S & 0 & 1.3 & 1.2 & 1.3 & 1.3 & 1.3 & 1.4 \\
\hline
\end{tabular}

Fig.1\&2 Growth of $K$. pneumoniae on MacConkey agar and $K$. pneumoniae on chromoagar
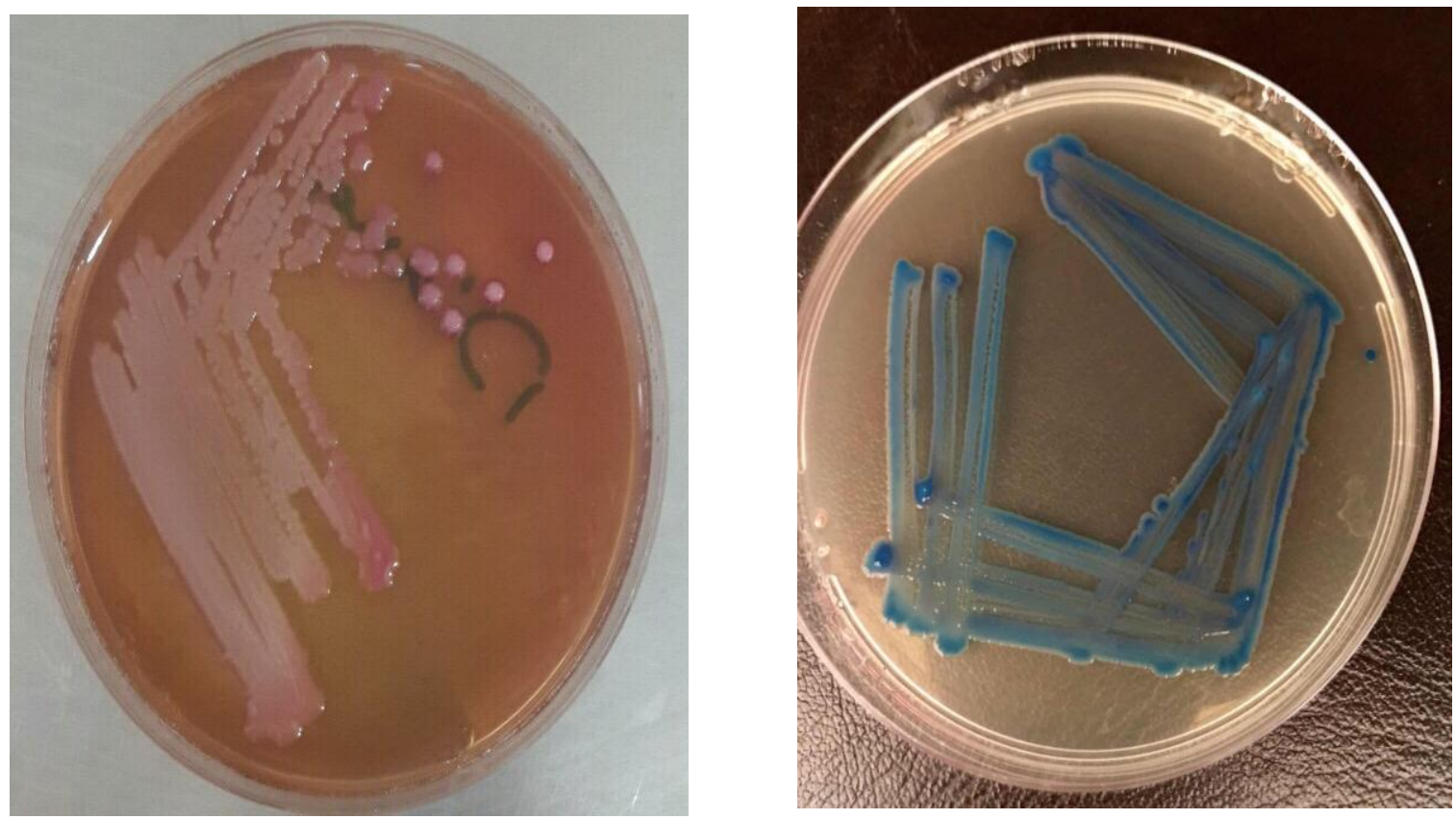

Fig.3 Klebsiella pneumoniae for EPI 20E

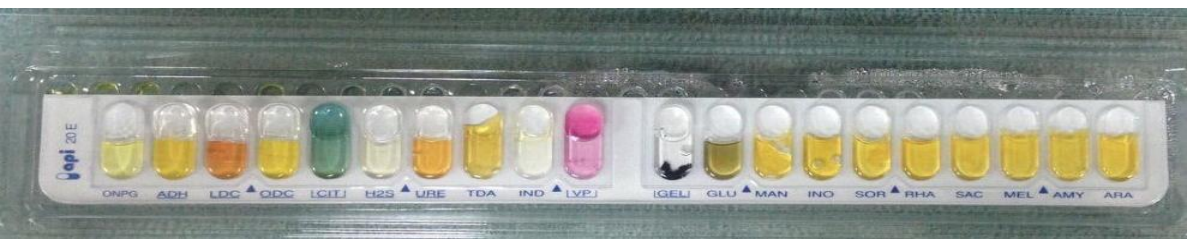


Fig.4\&5 Antimicrobial sensitivity test of $K$. pneumoniae and $K$. pneumoniae on Congo red agar
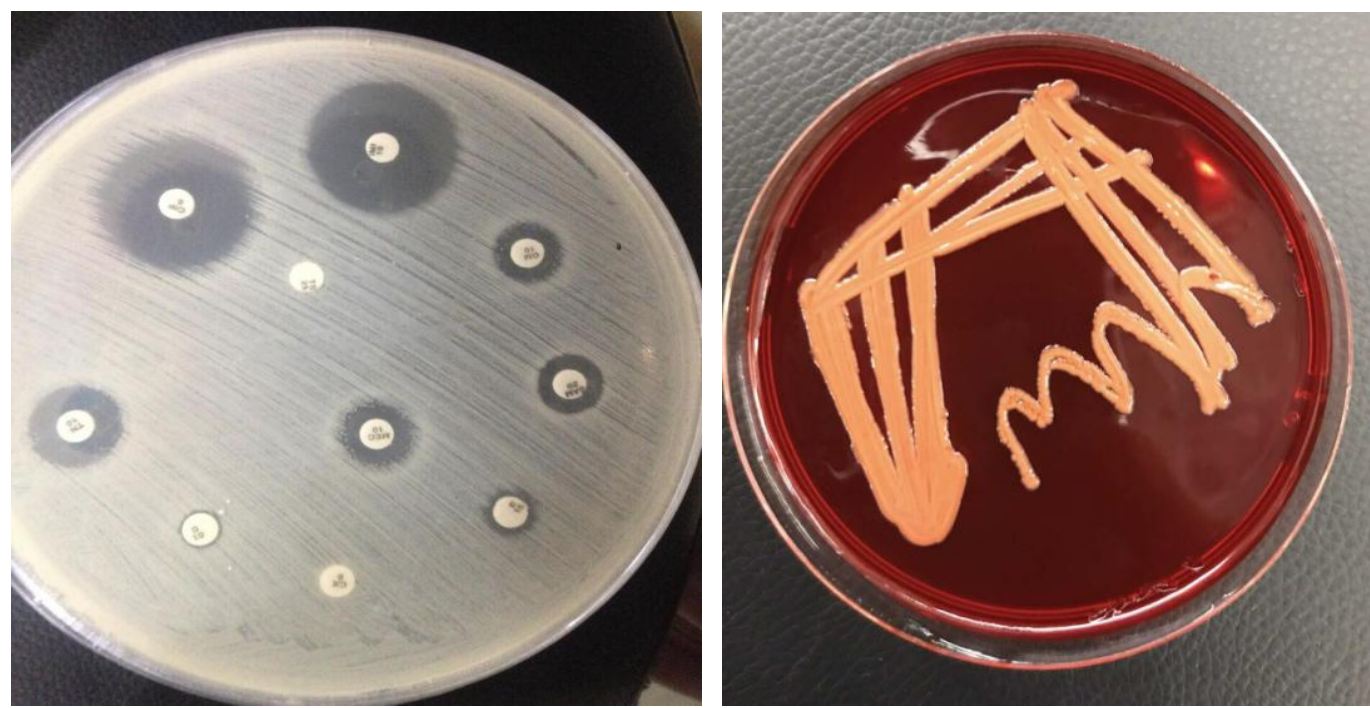

Fig.6 Exposed isolate on MacConkey agar by using methylene blue as laser dye

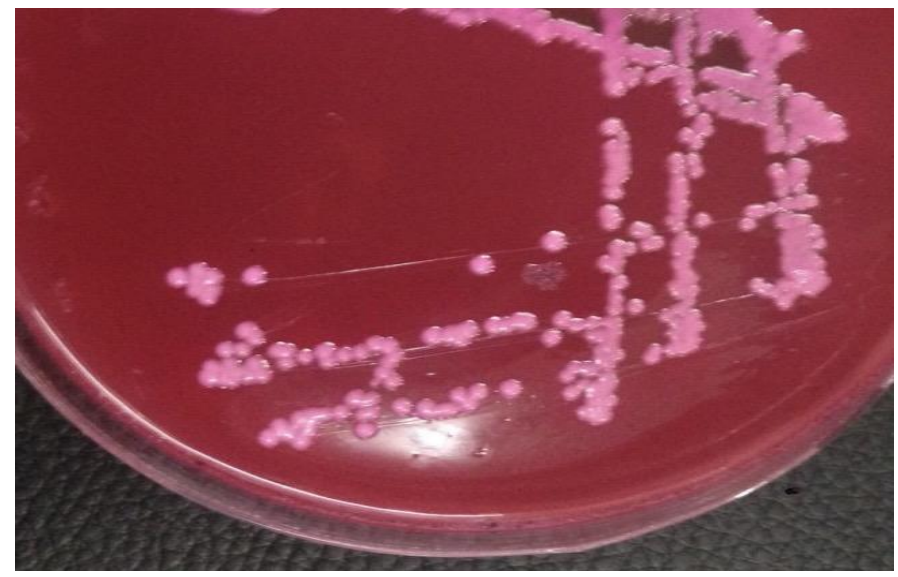

Fig.7\&8 Exposed isolate on MacConkey agar by using isolate on MacConkey agar and exposed Rhodamine 110 as laser dye by using anthocyanine as laser dye
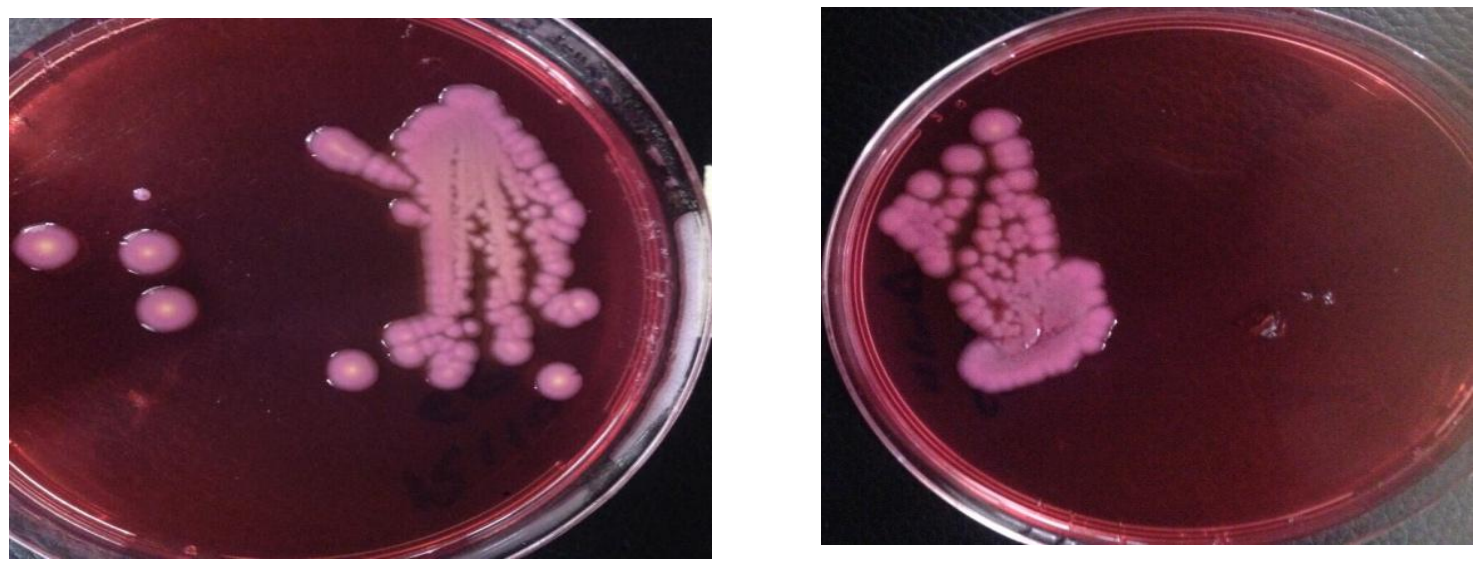
Table.5 Antimicrobial sensitivity test for isolate suspension with Anthocyanine dye that exposure to low power laser light at 532nm for $2 \mathrm{~min}$

\begin{tabular}{|l|l|l|l|l|l|l|l|}
\hline Antibiotic & Control & 1pass. & 2pass. & 3pass. & 4pass. & 5pass. & 6pass. \\
\hline IMI & 3.1 & 3.0 & 3.0 & 3.2 & 3.0 & 3.1 & 3.1 \\
\hline CIP & 3.0 & 3.0 & 2.9 & 3.0 & 2.9 & 3.0 & 2.8 \\
\hline GM & 1.3 & 1.5 & 1.6 & 1.6 & 1.5 & 1.5 & 1.5 \\
\hline CX & 0 & 0 & 0 & 0 & 0 & 0 & 0 \\
\hline TS & 0 & 0 & 0 & 0 & 0 & 0 & 0 \\
\hline MEC & 1.6 & 1.7 & 1.6 & 1.8 & 0 & 0 & 0 \\
\hline E & 1.0 & 0 & 0 & 0 & 0 & 0 & 0 \\
\hline TN & 1.8 & 1.8 & 2.0 & 2.0 & 1.7 & 2.0 & 1.8 \\
\hline SAM & 1.0 & 1.4 & 1.4 & 1.8 & 1.6 & 1.6 & 1.6 \\
\hline S & 0 & 1.3 & 1.2 & 1.3 & 1.3 & 1.3 & 1.4 \\
\hline
\end{tabular}

Fig.9 The Epi 20E to exposed isolate by using methylene blue as laser dye compared with control
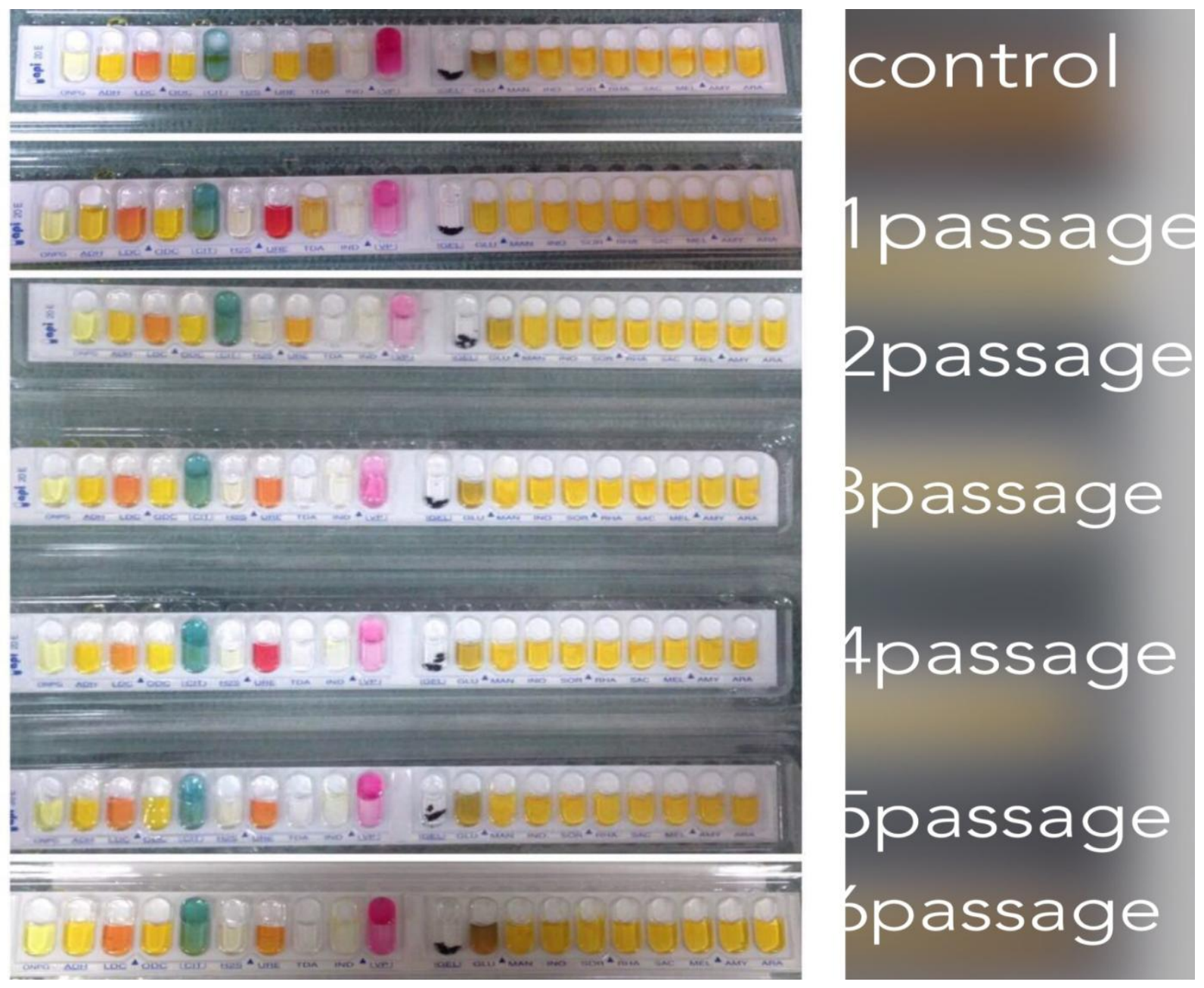
Fig.10 The Epi 20E to exposed isolate by using Rhodamine110 as laser dye compared with control

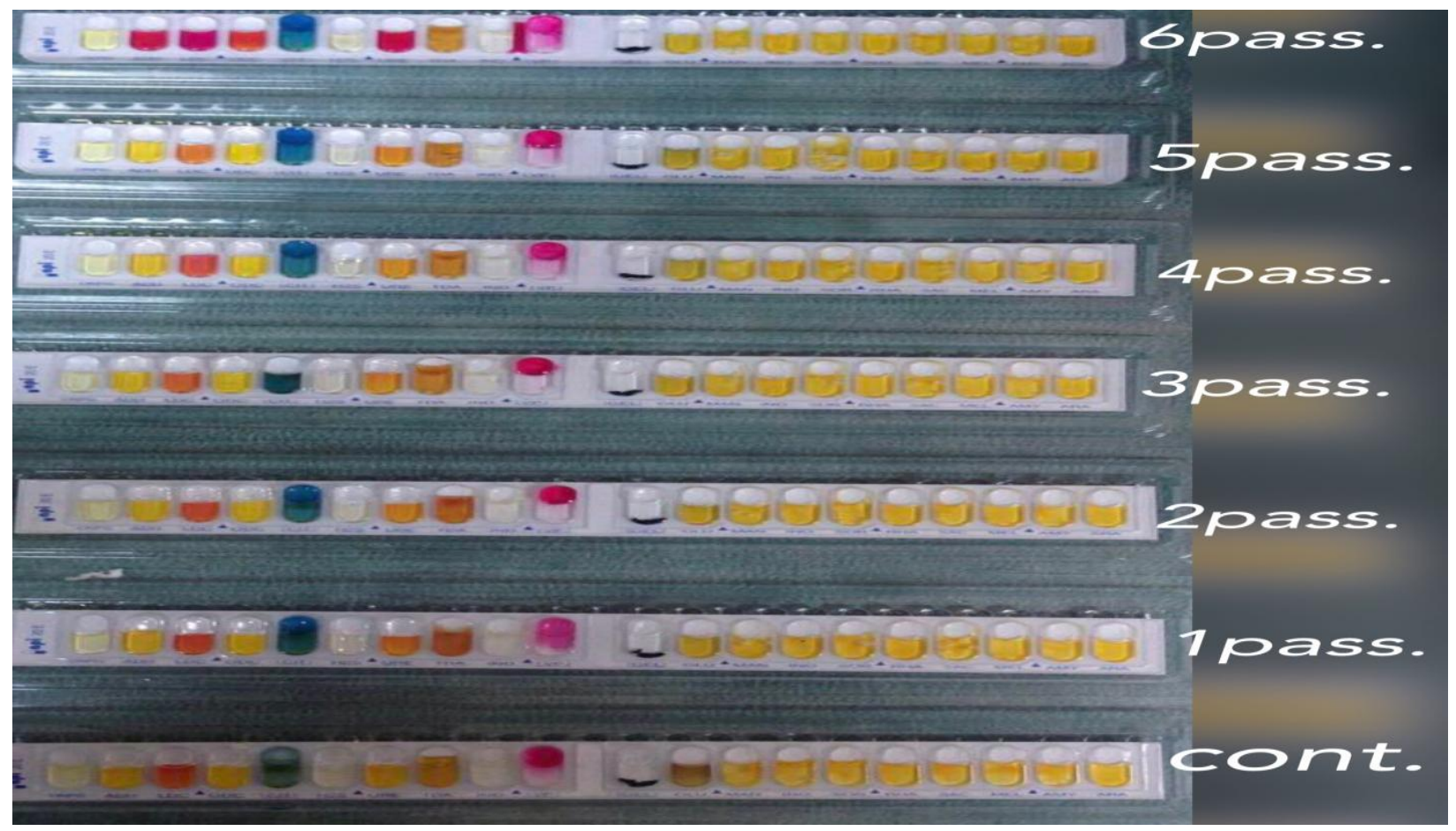

There is a decrease of the intracellular concentration of the antibiotic resulting from the occurrence of modifications in the bacterial outer membrane; increase of the activity of active efflux systems; decrease of the drug transport into the cell; and by enzymatic deactivation of aminoglycosides as (Talbot, 2013) mentioned, thus we suggested that the resistance to aminoglycosides may be retired due to exposed to laser (Table 4). On the other hand, the results of biofilm formation showed a negative result for all passages. The results of the exposure to low power laser light at $532 \mathrm{~nm}$ with using other organic dye (anthocyanine) were showed as that occurred with the Rhodamine 110 experiments, for morphologic and microscopic characteristics (Fig. 8).

As well as about antimicrobial sensitivity results also showed several variations especially with GM which converted from intermediate to sensitive, while about $S$, the exposed isolate was changed from resistance to intermediate. Whereas the exposed isolate showed changing the sensitivity for (MEC) to resistance in the last 3 passages, resistant bacteria generations was associated in most cases, either directly or indirectly with decreased virulence and fitness, genetic events also associated with the evolution of pathogen on virulence and fitness costs, in gramnegative, $\beta$-lactamases production was the most prevalent mechanism of $\beta$-lactam resistance, followed by permeability alterations, with extrusion by efflux pumps, and lesser extent penicillin binding protein (PBP) alterations as (Alejandro et al., 2013) reported, thus we suggested that the plotted of pathogenic $K$. pneumoniae to laser may make cell wall/cell membrane alteration. Whereas the gradual changing from resist of (SAM) to sensitive in 3rd, 4th and 5th, and 6th (Table 5). On the other hand, As other experiments, the results of biofilm formation showed a negative result for all passages which was represented no changes was occurred in compared. 
It can be concluded that the use of low power laser light with different organic dyes had an effect on bacterial virulence factors, and need further developed studies to improve these finding.

\section{References}

Alejandro Beceiro, Marìa Tomós, Germón Bou. 2013. Antimicrobial Resistance and Virulence: a Successful or Deleterious Association in the Bacterial World, Clin. Microbiol., 26(2): 185-230.

Alsalhi, M., V. Masilamani, K. Ibnaouf and O. Yassin. 2007. "Laser properties of a conjugate polymer (meh-ppv) in liquidexcimeric state", J. Laser Spectroscopy, 17: 243-501.

Balaji, G., R.K. Rekha, A. Ramalingam, A. Belfer-Cohen and E. 2011. " Nonlinear Characterization of Safranin O Dye for Application in Optical Limiting", $J$. ACTA Physica Polonica, 119,117-254.

Brooks, G.F., Bultel, J.S. \& Morse, S.A. 2001. Jawez Melnick and Adelbergs medical microbiology. 22nd Ed. Lange McGraw -Hill, N.Y.: 695 pp.

C.L.S.I. 2015. Performance Standards for Antimicrobial Susceptibility Testing; Twenty-Fifth Informational Supplement. CLSI document M100-S20. Clinical and Laboratory Standards Institute. Wayne, PA.

Grimont, P. and Grimont, F. 2005. Genus klebsiella In: Bergey's manual of synthetic bacteriology. Garrity, G.; Brenner, D.; Krieg, N. and Staley, J. eds.. 2ed Ed. The Proteobactria part B: the Gamma proteobacteria, pp. 685-694.

Holt, J.J., Krieg, N.R., Sneath, B.H.A., Staley, J.T. and Williams, S.T. 1994. Bergey's manual determinative bacteriology. 9th Ed. Williams and Wilken, Baltimore, PP. 175-348.

Horcajada, J.P., Soto, S., Gajewski, A., Smithson, A., Jiménez de Anta, M.T., Mensa, J., Vila, J., \& Johnson, J.R. 2005. Quinolone-resistant uropathogenic
Escherichia coli strains from phylogenetic group B2 have fewer virulence factors than their susceptible counterparts. J. Clin. Microbiol., 43(6): 2962-2964.

Houghton, J.L., Green, K.D., Chen, W., \& Garneau-Tsodikova, S. 2010. The future of aminoglycosides: the end or renaissance? Chem. Biochem., 11(7): 880-902.

Hsu, C.R., Lin, T.L., Pan, Y.J., Hsieh, P.F., Wang, J.T. 2013. Isolation of a bacteriophage specific for a new capsular type of Klebsiella pneumoniae and characterization of its polysaccharide depolymerase. PLoS ONE, 8(8): e70092.

Jagnow, J., Clegg, S. 2003. Klebsiella pneumoniae MrkD-mediated biofilm formation on extracellular matrix- and collagen-coated surfaces. Microbiol., 149(Pt 9): 2397-2405.

Li, B., Zhao, Y., Liu, C., Chen, Z., Zhou, D. 2014. Molecular pathogenesis of Klebsiella pneumoniae. Future Microbiol., 9(9): 1071-81. doi: 10.2217/fmb.14.48. [PubMed: 25340836]

Munoz-Price, L.S., Poirel, L., Bonomo, R. A., Schwaber, M. J., Daikos, G. L., Cormican, M., Cornaglia, G., Garau, J., Gniadkowski, M., Hayden, M. K., Kumarasamy, K., Livermore, D. M., Maya, J. J., Nordmann, P., Patel, J. B., Paterson, D. L., Pitout, J., Villegas, M. V., Wang, H., Woodford, N., \& Quinn, J. P. 2013. Clinical epidemiology of the global expansion of Klebsiella pneumoniae carbapenemases. Lancet Infect. Dis., 13(9): 785-796.

Munoz-Price, L.S., Poirel, L., Bonomo, R.A., et al. 2013. Clinical epidemiology of the global expansion of Klebsiella pneumoniae carbapenemases. Lancet Infect. Dis., 13(9): 785-796.

Murphy, C.N., Clegg, S. 2012. Klebsiella pneumoniae and type 3 fimbriae: nosocomial infection, regulation and biofilm formation. Future Microbiol., 7(8):991-1002. doi: 10.2217/fmb.12.74. 
Pan, Y.J., Fang, H.C., Yang, H.C., et al. 2008. Capsular polysaccharide synthesis regions in Klebsiella pneumoniae serotype K57 and a new capsular serotype. J. Clin. Microbiol., 46(7): 2231-2240.

Paterson, D.L., Ko, W.C., Von Gottberg, A., et al. 2004. International prospective study of Klebsiella pneumoniae bacteremia: implications of extended-spectrum betalactamase production in Nosocomial Infections. Ann. Intern. Med., 140(1): 26-32.

Piatti, G., Mannini, A., Balistreri, M., \& Schito, A.M. 2008. Virulence factors in urinary Escherichia coli strains: phylogenetic background and quinolone and fluoroquinolone resistance. J. Clin. Microbiol., 46(2): 480-487.

Podschun, R. \& Sahly, H. 1991. Hemagglatinins of Klebsiella pneumoniae and Klebsiella oxytoca isolated from different sources. Z $Z b I$. Hyg., 19: 46-52.

Podschun, R., Ullmann, U. 1998. Klebsiella sp. As nosocomial pathogens: epidemiology, taxonomy, typing methods, and pathogenicity factors. Clin. Microbiol. Rev., 11(4): 589-603.

Podschun, R., Ullmann, U. 1998. Klebsiella sp. as nosocomial pathogens: epidemiology, taxonomy, typing methods, and pathogenicity factors. Clin. Microbiol. Rev., 11(4): 589-603.

Saunders, R., Shiner, W., Conklin, T., Bennett, D., Thomas, G. 1980. Lasers, Mc GrawHillbook co.
Shimoda, K. 1984. Introduction to Laser physics. Springer-Velage.

Shon, A.S., Bajwa, R.P., Russo, T.A. 2013. Hypervirulent (hypermucoviscous) Klebsiella pneumoniae: a new and dangerous breed. Virulence, 4(2): 107118.

Shon, A.S., Russo, T.A. 2012. Hypervirulent Klebsiella pneumoniae: the next superbug? Future Microbiol., 7(6): 669671.

Steward, C.D., Rasheed, J.K., Hubert, S.K., Biddle, J.W., Raney, P.M., Anderson, G.J., Williams, P.P., Brittain, K.L., Oliver, A., McGowan, J.E., \& Tonover, F.C. 2001. Characterization of clinical isolates of Klebsiella pneumoniae from 19 laboratories using the national committee for clinical laboratory standards extended-spectrum B-lactamase detection methods. J. Clin. Microbiol., 165(2): 353-356.

Talbot, G.H. 2013. Beta-Lactam antimicrobials: what have you done for me lately? Ann. N.Y. Acad. Sci., 1277: 76-83.

Von Bathen, L.C., Paula, J.B., Cielinski, J., Pilonetto, M., Von Bahten, LC. 2014. Effects of low-level laser in in vitro bacterial culture and in vivo infected wounds. Rev Col Bras Cir. [periódico na Internet]., 41(1). Disponí- vel em

Vuotto, C., Longo, F., Balice, M.P., Donelli, G., Varaldo, P.E. 2014. Antibiotic Resistance Related to Biofilm Formation in Klebsiella pneumoniae Pathogens., 3(3): 743-58. doi: 10.3390/pathogens3030743.

\section{How to cite this article:}

Diana Fadhil Al-Saadi, Mouruj A. Al-Aubydi and Layla M. Al-Ameri. 2017. Assessment the Effects of Low Power Laser Light on Some Virulent Factors of Klebsiella pneumoniae Isolated from Respiratory Tract Infections. Int.J.Curr.Microbiol.App.Sci. 6(8): 2179-2190. doi: https://doi.org/10.20546/ijcmas.2017.608.258 